\title{
Influence of Punch Density and Fiber Blends on Thermal Conductivity on Nonwoven
}

\author{
S.M. Hosseini Varkiyani ${ }^{1}$, H. Rahimzadeh ${ }^{2}$, H. Bafekrpoor ${ }^{3}$ and Ali A.A. Jeddi ${ }^{*}, 1$ \\ ${ }^{I}$ Textile Engineering Department, Amirkabir University of Technology, Tehran 15914, Iran \\ ${ }^{2}$ Mechanical Engineering Department, Amirkabir University of Technology, Tehran 15914, Iran \\ ${ }^{3}$ Faculty of Engineering, Science and Research Campus, Islamic Azad University, Tehran, Iran
}

\begin{abstract}
One of the major applications for nonwoven fibrous system is as thermal insulation materials. Many factors may affect thermal properties. This research attempts to study the effects of punch density and fiber blends on heat transfer in nonwoven. For this purpose the samples, whose properties are analyzed by using static methods for measuring their thermal conductivity, were constructed in blends of polyester with polypropylene. The blend ratios are $100 \%$ PET, $80 / 20,60 / 40,40 / 60,20 / 80$, and $100 \%$ PP. Six samples were produced from each blend by changing the primary needle punch density to115, 135, 155, 175, and 195 punches per $\mathrm{cm}^{2}$. The secondary needle punch density was held constant at 120 punches per $\mathrm{cm}^{2}$. The temperature of the hot plate, i.e. the applied temperature, was $40^{\circ} \mathrm{C}$.
\end{abstract}

Experimental results show that with increasing punch density and pressure, heat transfer decreases. Moreover, the results indicate that the blending of fiber types causes a reduction in fabric heat transfer.

Keywords: Nonwoven, punch density, fiber blends, thermal conductivity, heat transfer.

\section{INTRODUCTION}

Thermal properties are important in many textile applications such as apparel, blankets, and sleeping bags. Thermal properties also affect performance in technical nonwoven usages, such as building insulation, automobiles, aircraft, and industrial process equipment. A textile structure is essentially a mixture of fibers, air, and moisture, each having distinctively different thermal properties. Thus thermal behavior of the system is the collective and interactive results of these three constituents. Nonwoven materials, because of savings in both space and weight, are one of the most important products in textiles that are being used as thermal insulating materials.

Heat transfer through a layer of fibers can occur by several mechanisms, that is free and forced convection, conduction through the solid fibers, conduction through the air in the interfiber spaces, and radiation [1]. Viskanta [2] stated that due to interactions, these mechanisms, strictly speaking, are not separable. Many investigators in this field have studied these mechanisms, their interactions, and relative contributions [3-5]. There appears, however, to be a consensus among all investigators that the major components of heat transfer through nonwoven systems are conduction by air and radiation [1].

There are both experimental and theoretical investigations in heat transfer through heterogeneous nonwoven fibrous systems. Heat transfer through fiber beds by means of radiation and conduction was reported by Stuart and

*Address correspondence to this author at the Textile Engineering Department, Amirkabir university of Technology, Tehran 15914, Iran; Tel: +98-21-66400245; Fax: +98-21-64542685; E-mail: ajeddi@aut.ac.ir
Holcombe [5]. They derived heat transfer equations that take into account the shadowing effect, i.e., the portion of the radiated heat that is absorbed by fibers in its path. Jirsak, et al. [6] developed and tested a new dynamic measurement method for thermo-insulating properties of textiles, and considered the feasibility of testing the thermal behavior of textiles using this approach. They also tested the same samples using a static method. Finally, they did not recommend the dynamic method for porous media like textiles since they are complex and extremely sensitive to pore size, pore nature, and distribution and are thus very unstable.

The thermal conductivities of multilayered nonwoven fabrics, using glass and ceramic fibers, were determined at steady state by Mohammadi, et al. [7]. They determined that the thermal conductivity of needled nonwoven structures can be predicted with a high degree of accuracy using a model with fabric thickness, porosity, and structure along with applied temperature. They also presented a theoretical equation for the combined thermal conductive, convective, and radiative heat flow through heterogeneous multilayer fibrous materials [8]. They concluded that by adding glass layers to the sample, the radiative conductivity is increased, since the mean free path for movement of the photons passing through the channels in the glass web is higher. Mean free path was defined as the distance traveled by a photon before heating the surface of surrounding fibers [8].

The research reported here discusses the influence of fiber blend percentage on the thermal conductivity of nonwoven materials. The needle punching density was also varied in order to study the effect of nonwoven layer densities on heat transfer characteristics. Samples were also 
compressed in an effort to study the effect of pressure on thermal conductivity.

\section{MEASURING DEVICE}

There are different ways to determine the thermal conductivity which is the most important parameter describing the thermal behavior of a material. In static measurement the thermal conductivity of a material is determined by:

$k=\frac{Q \Delta \mathrm{x}}{\mathrm{A}\left(\mathrm{T}_{1}-T_{2}\right)}$

where $\mathrm{k}$ is the thermal conductivity $\left(\mathrm{W} \mathrm{m}^{-1} \mathrm{k}^{-1}\right), \mathrm{Q}$ is the heat flux (W), $\Delta \mathrm{x}$ is the thickness of the sample (m), $\mathrm{A}$ is the area of the test plate(or sample) $\left(\mathrm{m}^{2}\right)$, and $\Delta \mathrm{T}$ is the temperature difference between the two surfaces of the specimen $\left({ }^{\circ} \mathrm{C}\right)$ (See Fig. 1).

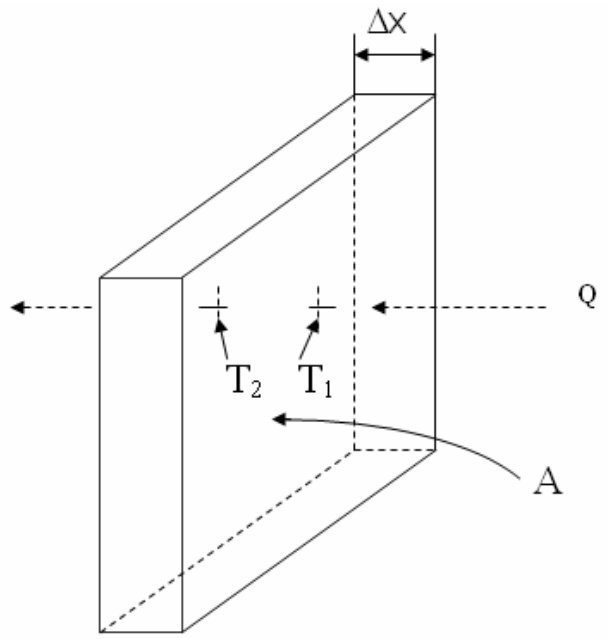

Fig. (1). Steady state conduction of heat through a solid slab.
It is more difficult to determine $\mathrm{k}$ using a dynamic method. There are several theories for predicting the heating process of materials dynamically, including those for heat conduction in a finite slab [9] and those for a semi - infinite body [10].

A static measurement was determined using Thermal Conductivity Measuring Apparatus, HVS-40-200 SG Model. The procedure involves placing a nonwoven fabric between two metal plates and observing the increase in temperature with time. A schematic diagram of the apparatus is shown in Fig. (2). This apparatus is designed for measuring thermal conductivity of metals.

\section{MATERIALS AND METHODS}

Six different blended webs were produced from polyester and polypropylene with blend ratios of $100 \%$ PET, 80/20, $60 / 40,40 / 60,20 / 80$, and $100 \%$ PP with circular cross section. The length and fineness of all fibers used in producing these webs were $90 \mathrm{~mm}$ and 15 denier respectively. All webs were produced by using a Thibeau carding machine. Ten of these carded webs were stacked using an Asselin cross lapper machine. The next stage was primary and secondary needling using a Fehrer needling machine with needles $15 \times 18 \times 32 \times 3.5 \quad$ R333 G1002. However, the primary needling variations have more important role in industrial processing than secondary needling. For this reason, the punch density of secondary needling was held constant at 120 punches per $\mathrm{cm}^{2}$, while in primary needling it was $115,135,155,175$, or 195 punches per $\mathrm{cm}^{2}$. This range is the practical variations from the minimum to maximum values of primary needling of Fehrer needling machine. The needling depth in primary needling was $15.65 \mathrm{~mm}$ and in secondary needling it was $16.48 \mathrm{~mm}$. Tables 1 and $\mathbf{2}$ show the thickness and the web void fraction respectively of all fabrics at various punch densities. The thickness reported is an average of 10 measurements from each sample.

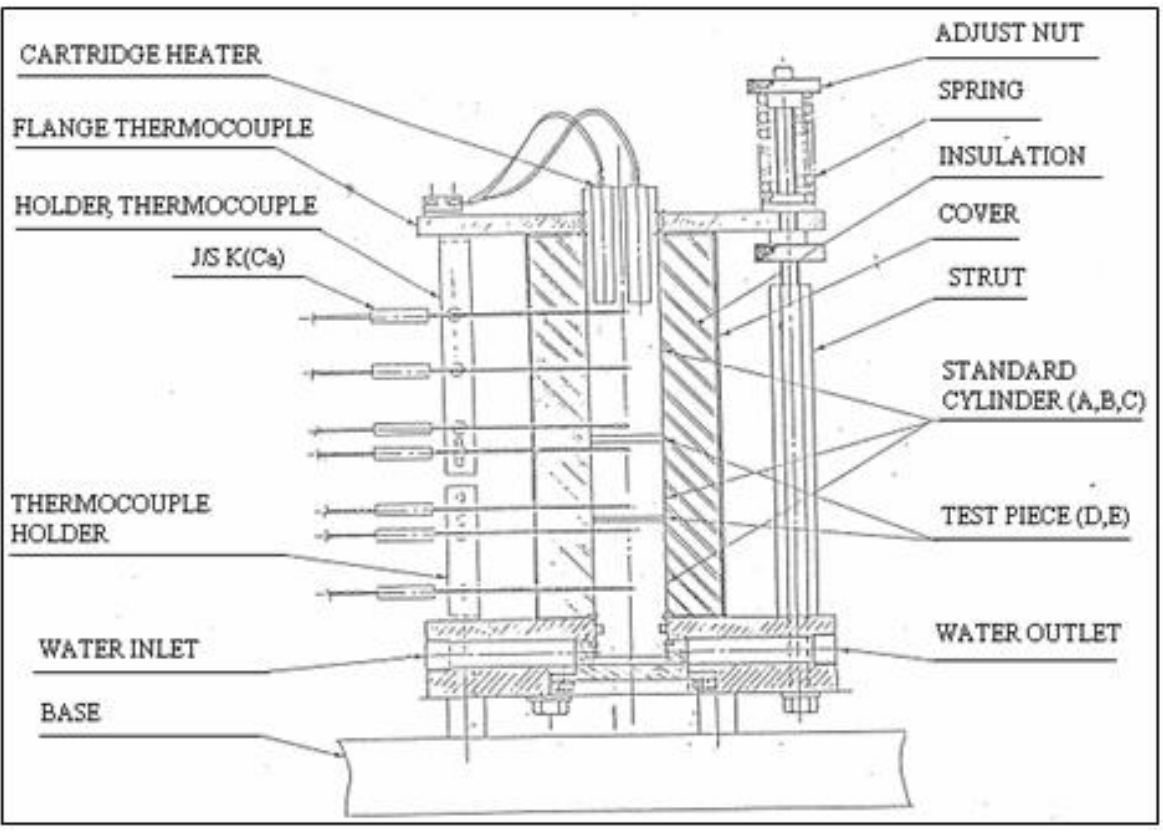

Fig. (2). A schematic diagram of the thermal conductivity measuring apparatus. 
Table 1. The Thickness of the Fabrics

\begin{tabular}{|c|c|c|c|c|c|c|}
\hline \multirow{2}{*}{$\begin{array}{c}\text { Pabrics } \\
\text { Primary Punch Density } \\
\text { (punches per } \mathbf{~ m}^{2} \text { ) }\end{array}$} & \multicolumn{4}{|c|}{ Fabric Thickness (mm) } \\
\cline { 2 - 7 } & $100 \%$ PET & $\mathbf{1 1 5}$ & $\mathbf{1 3 5}$ & $\mathbf{1 5 5}$ & $\mathbf{1 7 5}$ & $\mathbf{1 9 5}$ \\
\hline \hline $80 \%$ PET, 20\% PP & 5.27 & 5.10 & 5.06 & 4.45 & 4.40 \\
\hline $60 \%$ PET, 40\% PP & 4.12 & 3.95 & 3.90 & 3.83 & 3.70 \\
\hline $40 \%$ PET, $60 \%$ PP & 3.75 & 3.69 & 3.63 & 3.62 & 3.60 \\
\hline $20 \%$ PET, 80\% PP & 4.35 & 4.14 & 4.10 & 3.71 & 3.70 \\
\hline $100 \%$ PP & 4.83 & 4.60 & 4.52 & 4.42 & 4.23 \\
\hline $100 \%$ PET compressed & 5.70 & 5.40 & 5.25 & 5.20 & 5.00 \\
\hline
\end{tabular}

Table 2. The Web Void Fraction of the Fabrics

\begin{tabular}{|c|c|c|c|c|c|c|c|c|c|c|}
\hline \multicolumn{10}{|c|}{ Web Void Fraction } & \multirow{4}{*}{ Fabrics } \\
\hline \multicolumn{10}{|c|}{ Primary Punch Density (Punches per $\mathrm{cm}^{2}$ ) } & \\
\hline \multicolumn{2}{|c|}{195} & \multicolumn{2}{|c|}{175} & \multicolumn{2}{|c|}{155} & \multicolumn{2}{|c|}{135} & \multicolumn{2}{|c|}{115} & \\
\hline TC & WVF & TC & WVF & TC & WVF & TC & WVF & TC & WVF & \\
\hline 0.0322 & 0.842 & 0.0326 & 0.851 & 0.0373 & 0.878 & 0.0376 & 0.865 & 0.0391 & 0.872 & $100 \%$ PET \\
\hline 0.0274 & 0.876 & 0.0282 & 0.879 & 0.0286 & 0.885 & 0.0290 & 0.872 & 0.0303 & 0.884 & $80 \%$ PET, $20 \%$ PP \\
\hline 0.0258 & 0.824 & 0.0260 & 0.816 & 0.0263 & 0.853 & 0.0264 & 0.848 & 0.0268 & 0.858 & $60 \%$ PET, $40 \%$ PP \\
\hline 0.0268 & 0.815 & 0.0270 & 0.802 & 0.0297 & 0.845 & 0.0304 & 0.827 & 0.0312 & 0.845 & $40 \%$ PET , $60 \%$ PP \\
\hline 0.0301 & 0.803 & 0.0318 & 0.801 & 0.0327 & 0.840 & 0.0332 & 0.829 & 0.0349 & 0.833 & $20 \%$ PET, $80 \%$ PP \\
\hline 0.0373 & 0.860 & 0.0383 & 0.863 & 0.0388 & 0.867 & 0.0391 & 0.856 & 0.0393 & 0.863 & $100 \% \mathrm{PP}$ \\
\hline
\end{tabular}

WVF: Web Void Fraction; TC: Thermal Conductivity.

The procedure for using the Thermal Conductivity Measuring Apparatus, HVS-40-200 SG Model calls for the use of two of the same samples. The second sample is under pressure and this pressure is believed to influence the heat transfer properties of nonwoven fabrics. Also, having two nonwoven samples with exactly the same properties is impossible. For these reasons, the arrangement of samples in all experiments was altered and a metal cylinder with $4 \mathrm{~mm}$ thickness and $40 \mathrm{~mm}$ diameter was used instead of a second nonwoven sample. This setup reduced possible errors and increased the validity of results. As shown in the Fig. (2), several thermocouples were used in order to determine the exact temperature difference, $\Delta \mathrm{T}$, between the upper and lower surfaces of the sample. The samples were circles of the same diameter $(40 \mathrm{~mm})$ as the metal plate. The applied temperature was $40^{\circ} \mathrm{C}$. Data was collected each 20 minutes until steady state was reached.

With reference to the above modification, the sample arrangement should be considered as two conductors in series (See Fig. 3); one a standard of known conductivity (metal cylinder) and the other a sample whose thermal conductivity is to be measured (nonwoven sample).

Based on the equation of a steady state conduction of heat through two solids slabs in series [1], the nonwoven samples thermal conductivity is calculated as follows:

$$
\frac{K_{1} \Delta \mathrm{T}_{1}}{\Delta \mathrm{X}_{1}}=\frac{K_{2} \Delta T_{2}}{\Delta X_{2}}
$$

where subscript 1 denotes the standard metal cylinder and 2 denotes the test sample. Using $T_{1}, T_{2}, T_{3}$, and $T_{4}$ which are read from the apparatus and the temperature gradient diagram of the apparatus, the fabrics conductivity can be calculated as follows:

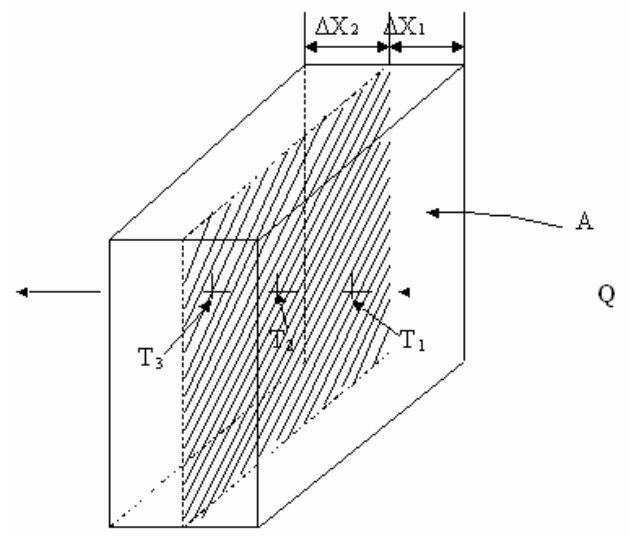

Fig. (3). Steady state conduction of heat through two solid slabs in series. 


$$
K_{f a b}=\frac{K_{f a b}^{\prime}}{0.85968}
$$

where

$$
K_{f a b}^{\prime}=\frac{10.67\left(T_{2}-T_{1}\right)\left(\Delta X_{f a b}\right)}{\left[1.167\left(T_{3}-T_{2}\right)-0.167\left(T_{4}-T_{1}\right)\right]}
$$

and

$\Delta \mathrm{X}_{\mathrm{fab}}=$ the fabric thickness $(\mathrm{mm})$ in the apparatus.

\section{RESULTS AND DISCUSSION}

4.1. The Effect of Punch Density on Thermal Conductivity

The punch density $\left(\mathrm{pn} / \mathrm{cm}^{2}\right)$ is altered by changing the speed of delivery roller per minute. The setting of punch density causes variation in web void fraction. Fig. (4) shows the relationship between web void fraction and punch density for different blends of samples. Fig. (5) presents typically for $100 \%$ polyester, with nonwoven containing 15 denier fibers, with increasing of punch density, the thickness

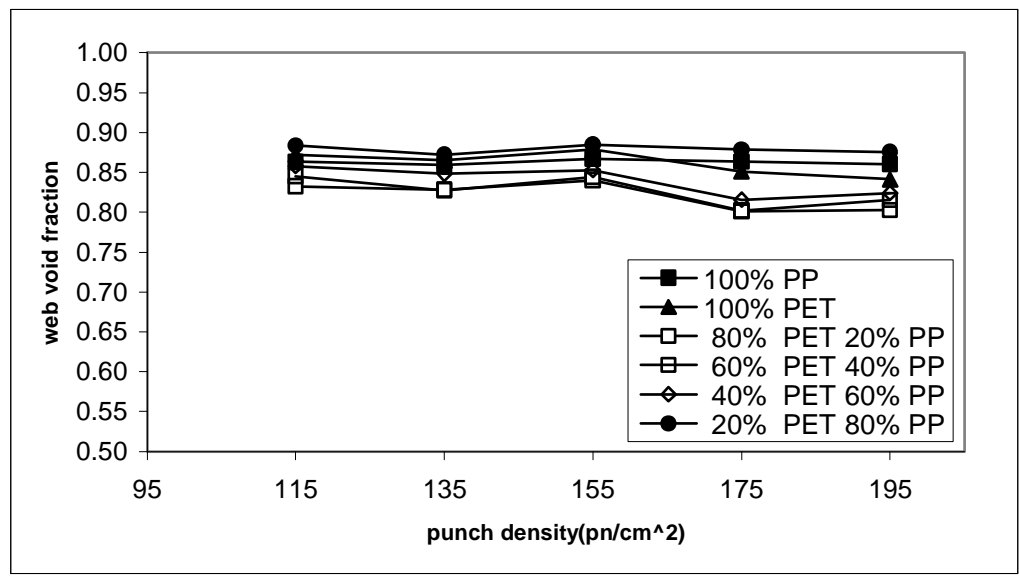

Fig. (4). The effect of punch density on web void fraction for all blends sample.

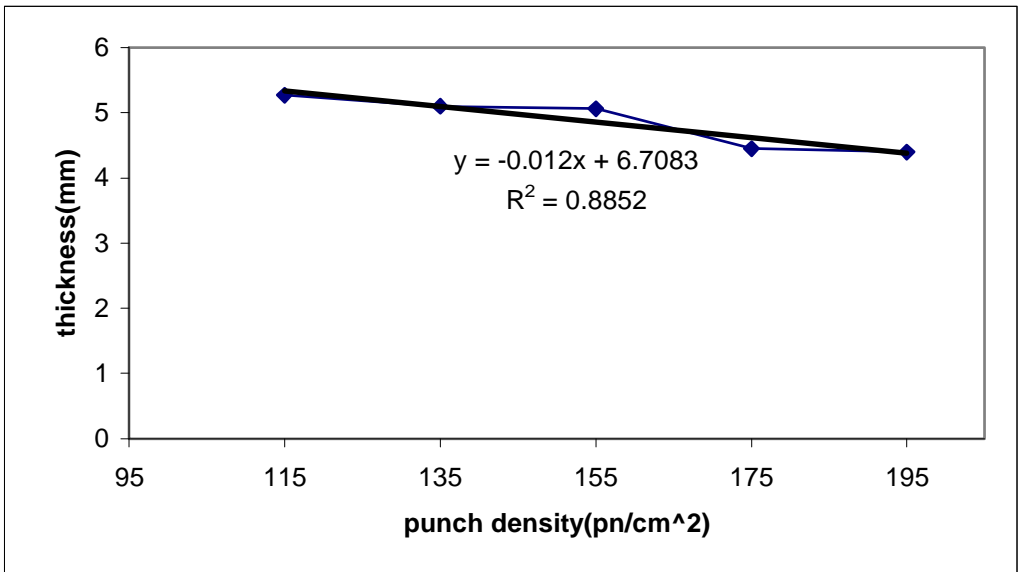

Fig. (5). The effect of punch density on the fabric thickness (100\% polyester).

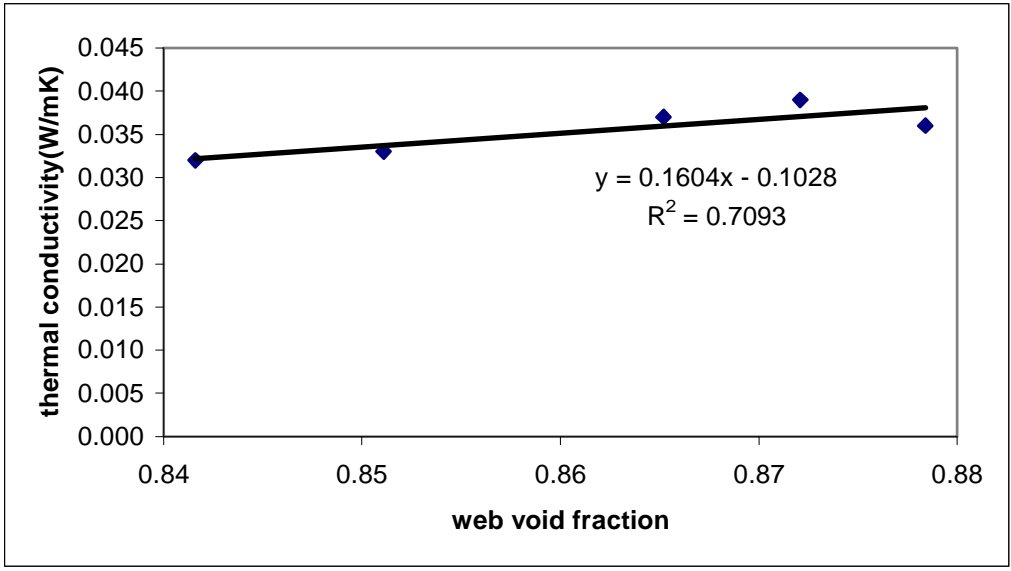

Fig. (6). The effect of web void fraction on fabric thermal conductivity (100\% polyester). 
of the fabric decreases. Therefore, as Fig. (6) shows, lower thermal conductivity consigned with increasing web void fraction. Comparing these figures, it can be understood that with increasing of punch density, the structure is being more packed, thus causing higher tortuosity or a lower mean free path, which generally results in more heat being blocked. The mean free path for movement of photons passing through the channels is greater in low web void fraction.

For the structures discussed here, higher mean free path implies lower tortuosity or a more open structure, which in turn implies that the thermal conductivity is increased in the sample by reducing of punch density.

\subsection{The Effect of Fiber Blend on Thermal Conductivity}

As seen in Table 2, a comparison of $100 \%$ PET and $100 \%$ PP shows that the sample with $100 \%$ PET makes a better insulating material, especially at higher punch rates. This is caused by the higher melting point of PET fibers.

The melting point of PET fibers is $260^{\circ} \mathrm{C}$ and only $170^{\circ} \mathrm{C}$ for PP fibers. This means that the heat capacity of PET fibers is higher than that of PP fibers which causes PET to be a better insulating fiber. In other words, PET fibers have a higher glass transition temperature than PP fibers. Thus more time is required for PET fibers to heat up and radiate energy, which causes them to be a better insulating material.

There is also another reason for this phenomenon and that is more elongation of PP fibers, causing PP webs to have higher packing densities and thus a higher tortuosity. This causes the heat transfer due to radiation to decrease thus improving the insulation properties. This elongation caused the blended samples to be more efficient as insulating materials than the unblended samples. This is an opposite result from that reported by Martin and Lamp [1] where they stated that fabric structure is more important than fabric material.

Polypropylene fiber has a higher elongation and lower strength than PET fiber. It is possible that during needling PP fibers elongate and thus are pulled farther down into the web than are PET fibers, causing an increase in packing density. Consequently, it is possible to have a higher packing density in fabric blends of PP and PET fibers than with PET fabrics. An increase in packing density increases tortuosity and reduces mean free path causing a reduction in thermal conductivity. This reduction in thermal conductivity caused blended samples to be better insulating materials than the non- blended samples. Among the blended samples, $60 \%$ PET with $40 \%$ PP is the most suitable fabric for decreasing of heat transfer.

\subsection{The Effect of Pressure on Thermal Conductivity}

Fig. (7) shows the effect of compression on thermal conductivity for a $100 \%$ PET nonwoven.

In order to test the effect of pressure on the thermal conductivity, a $3.5 \mathrm{~kg}$ weight was used to compress the sample. Fig. (7) show that the compressed sample (b) gives insulating properties that are superior to the non-compressed (a) sample. Whenever a nonwoven fabric is under pressure, the packing density is increased. This is due to an increase in tortuosity and decrease in mean free path resulting from distortion of channels in the nonwoven fabric. Thus as expected the results indicate that the thermal conductivity on nonwoven material decrease as the material is compressed.

\section{CONCLUSIONS}

The experimental work reported in this paper studies the thermal conductivity of needle punched nonwovens. The fabric structure is varied by changing the primary needle punch density. Blend ratio of polyester and polypropylene fibers used in the webs is also varied. In evaluating the effective thermal conductivities of nonwoven materials a static technique is used and the effect of fabric parameters on the thermal conductivity is studied.

Results show that the effective thermal conductivity of the needled nonwoven structures used in this work can be explained by variation in the mean free path for movement of photons passing through the channels in the structures. Higher mean free path implies lower tortuosity, a more open structure or lower packing density. Fabric density was altered by changing the primary needling density.

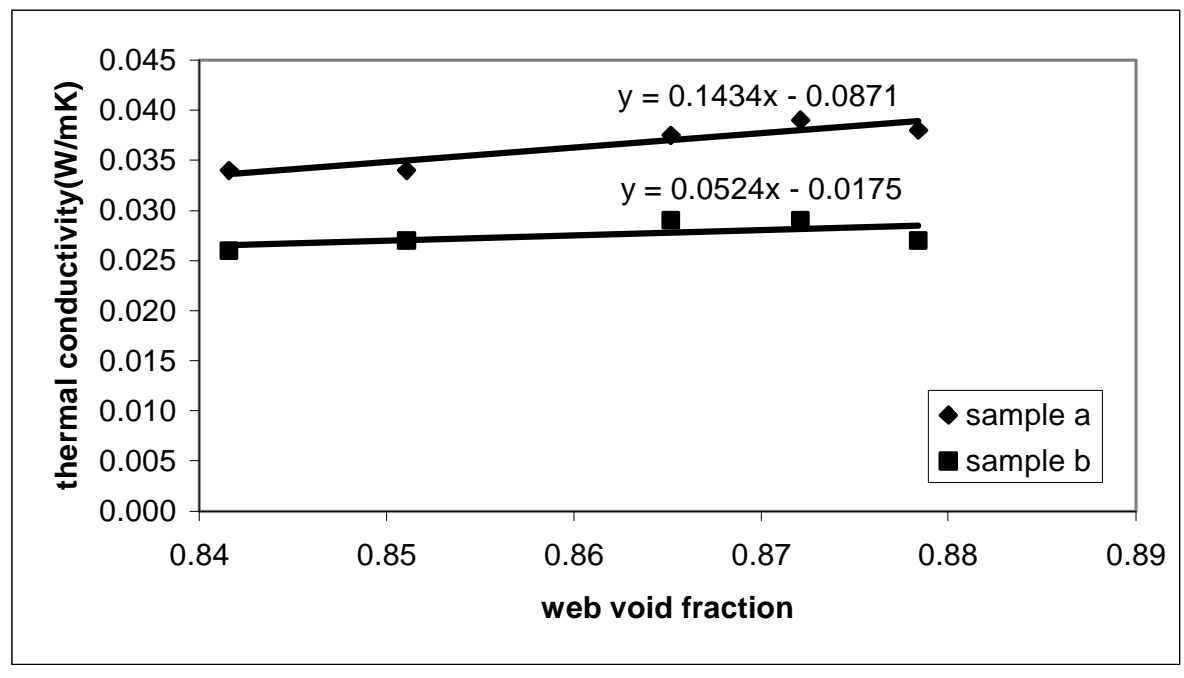

Fig. (7). The effect of compression on the fabric thermal conductivity. 
The results obtained in this work are as follows:

1. The thermal conductivity of nonwovens is increased by reducing punch density.

2. For test conditions used, the thermal conductivity of nonwovens is decreased by increasing pressure on the fabric.

3. The thermal conductivity of fabrics with $100 \%$ PET is lower than that of $100 \%$ PP fibers. However, fabrics produced from a blend of polyester and polypropylene has better insulating potential than fabrics with either $100 \%$ polyester or $100 \%$ polypropylene.

4. In this work, the nonwoven with $60 \%$ PET and $40 \%$ PP showed the lowest thermal conductivity and thus the best insulating potential.

\section{REFERENCES}

[1] J. R. Martin, and G. E. R. Lamp, "Measurement of thermal conductivity of nonwoven using a dynamic methods", Textile Res. J., vol. 57, pp. 721-727, 1987.
[2] R. Viskanta, and J. R. Grosh, "Heat transfer by simultaneous conduction and radiation in an absorbing medium", J. Heat Trans., vol. 2, pp. 63-72, 1962.

[3] N. E. Hager, and R. C. Steere, "Radiant heat transfer in fibrous thermal insulation", J. Appl. Phys., vol. 38, pp. 4663-4668, 1967.

[4] B. Farnoworth, "Mechanism of heat flow through clothing insulation", Textile Res. J., vol. 53, pp. 717-725, 1983.

[5] M. Stuart, and B. V. Holcombe, "Heat transfer through fiber beds by radiation with shading and conduction", Textile Res. J., vol. 54, pp. 149-157, 1984.

[6] O. Jirsak, T. Gok, B. Ozipek, and N. Pan, "Comparing dynamic and static methods for measuring thermal conductive properties of textiles", Textile Res. J., vol. 68, pp. 47-56, 1998.

[7] M. Mohammadi, P. Banks-Lee, and P. Ghadimi, "Determining effective thermal conductivity of multilayered nonwoven fabrics", Textile Res. J., vol. 73, pp. 802-808, 2003.

[8] M. Mohammadi, P. Banks-Lee, and P. Ghadimi, "Determining radiative heat transfer through heterogeneous multilayer nonwoven materials", Textile Res. J., vol. 73, pp. 896-900, 2003.

[9] J. Crank, "The Mathematics of Diffusion", $2^{\text {nd }}$ ed., Clarendon Press, Oxford, 1975.

[10] Erwin, Kreyszig, "Advance Engineering Mathematics", $7^{\text {th }}$ ed., John Wiley \& Sons, NY, 1993.

(C) Varkiyani et al.; Licensee Bentham Open.

This is an open access article licensed under the terms of the Creative Commons Attribution Non-Commercial License (http://creativecommons.org/licenses/by$\mathrm{nc} / 3.0 /$ ), which permits unrestricted, non-commercial use, distribution and reproduction in any medium, provided the work is properly cited. 